\title{
DESIGN AND DEVELOPMENT OF ADVANCED MICROCONTROLLER BASED SOLAR BATTERY CHARGER AND SOLAR TRACKING SYSTEM
}

\author{
Maruti Pammar ${ }^{1}$, Santosh Chavan ${ }^{2}$ \\ ${ }^{I}$ M.Tech Student Department of ECE, M.S. Ramaiah Institute of Technology, Bangalore (Karnataka), India \\ ${ }^{2}$ Assistant Professor E\&C Dept RRCET Bangalore
}

\begin{abstract}
Solar energy harvesting is blooming across the world, and it is being used for variety of applications; storing the electricity generated from the sunshine for future use is one among these.

Batteries are the main components used in off grid solar power harvesting systems to store the power generated from sun light. For storing the electricity into the batteries, we need charge controllers which will control the amount of current flowing into a battery. Conventional battery chargers may fail in monitoring the battery health and are not so intelligent to decide when to charge battery, and are unable to detect faults in a battery charging circuit. Most of time solar panels are mounted on a roof or on poles; due to this the solar modules will not get the enough sunshine to generate electricity throughout the day. And hence the conversion efficiency will be very less. If we use some mechanism to make solar panels to be facing the sun always, we can maximize the incidence of sun radiation on the panel surface and hence the efficiency; this mechanism that makes the solar panel to move according to the sun position is known as solar tracker. In this paper design of an efficient battery charger and smart single axial solar tracker is proposed and developed; that will take care of battery health and monitor the charging and discharging of battery (like deep discharging, overcharging protection, and control of external loads).And also has an option to charge battery using AC supply in case of low light intensity (during rainy seasons and night hours). The single axis solar tracker will track the sun moment throughout the day and rolls back to the east position once sun sets, and waits for sun to rise. This makes solar panel always facing the sun and enhances the overall system efficiency. The battery charger and solar tracker control programs are implemented in an advanced microcontrollerARM7 (LPC2148) which has most advanced features compared to other microcontrollers.
\end{abstract}

Keywords:ARM7 microcontroller, battery, charger (charge controller), conversion efficiency, deep discharging, overcharging, low light intensity, off-grid solar power harvesting system, solar energy, solar tracker. $* * *$

\section{INTRODUCTION}

The change in atmosphere and environmental pollution is now not a topic of discussion and debate but it is an actual consequence what we are facing in our day today life; this is as a result of extensive fossil fuel exploitation in almost all human activities. These impacts made earth's environment wormer and depletion in ozone layer, acid rain, and green house effects etc. One of the best solutions to overcome all these ill effects is to go for renewable energy resource such as solar energy, wind energy, Geo thermal energy etc.

Among the various renewable energies, solar energy is usually the best choice for the following reasons [1]:

A solar power system has no moving parts; it has as better reliability and 25 year warranty ;it requires less monitoring, no much expensive maintenance; totally silent in operation; less susceptible to lightning damage and high wind damage; no much space is required, in most cases the panels can be installed on a roof; Energy output is predictable, and quick installation can be done with less cable required.

A solar Power system is as shown in figure 1

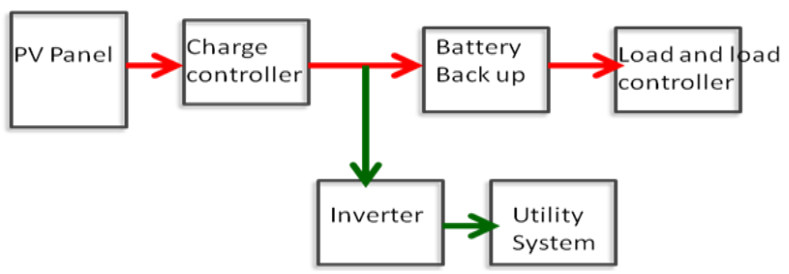

Fig-1: Solar energy harvesting system's components

It consists of solar panels, charge controllers, battery backup or Inverters. To controls the charging and discharging of battery backups we need Charge controllers, hence charge controller is a main part of the solar power system where solar energy is used to charge UPS systems or vehicle batteries. 


\section{PRESENT METHEDOLOGIES \&ISSUES}

Batteries are used to store the energy as an energy bank for emergency and night hour usage in domestic and also in industrial applications. To charge these batteries from the sun light we have to give rated amount of current for rated time duration. If we supply excess current, that may damage the battery and if we overcharge it for long duration of time the batteries life span will come down.

The conventional battery chargers available in market have limited features. And some time they do not monitor the battery health properly, and may let the battery to undergo deep discharge or overcharge. If a battery undergoes into deep discharge, it is very difficult to recharge it using normal battery charger; since the electrode plates of battery will be fully sulfated, this resists the charging. To charge a deep discharged battery we need to supply a very large current to reverse the chemical reactions which took place during discharging. If we supply huge current to a deep discharged battery, battery will get damaged. And if we let a battery to be in charging process for a long duration (over charging), gassing of hydrogen and oxygen occurs at the electrode plates and wash away the active material coated on the plates this again leads failure of battery hence an intelligent battery charger is necessary to take care of these problems.

A Monocrystaline silicon PV cell has higher conversion efficiency (aprox22\%) but higher cost hence these are not affordable for commercial applications. For most of domestic and commercial applications poly silicon cells are preferred but the conversion efficiency (7-8\%) is very low as compared to monocrystaline[1].

To enhance the efficiency of a PV power system we have to

- Improve Conversion efficiency of PV cells

- Improve Battery storage Technology

- Use solar ray concentrators

- Use solar trackers

- Use algorithms like maximum power point tracking

- Use sophisticated Battery chargers.

First two options mentioned above are ongoing research; we can improve the efficiency using combination of last three options.

Most of time solar cells are fixed on a roof or on pole. Solar radiation is not same throughout the day and it varies with seasons hence the conversion efficiency is always less. This can be improved by employing some mechanism where the solar panels are made always facing the sun. This technique is called solar tracking.

There are some algorithms known as Maximum Power point Tracking algorithms such as fuzzy logic algorithms (Perturb and observe algorithms and its variants), biological swarm chasing algorithms, Incremental conductance method etc can improve the efficiency; But these are very complex and require lot of processing and also each of these have their own merits and demerits. Therefore in this paper a simple solar tracker and a smart battery charger is proposed to enhance the system overall efficiency.

\section{CHARACTERISICS OF PV PANEL}

An electrical equivalent model to explain the behavior of a solar cell is as shown in figure 2

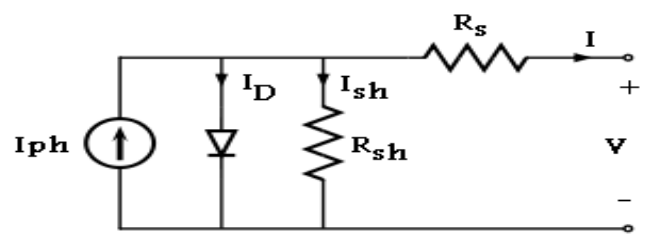

Fig-2: Electrical equivalent of a solar cell $[2,17]$

The current equation of solar cell is given as

$$
\mathrm{Iph}=\mathrm{ID}+\mathrm{Ish}+\mathrm{I}
$$

OR

$$
I=I p h-I o\left(\exp \left(\frac{q(V+I R s)}{n K T}-1\right)-\frac{(V+I R s)}{R s h}\right.
$$

Where

I: Output current (Amp)

Iph: Photo generated current (Amp)

ID: Diode current (Amp)

Ish: Shunt current (Amp)

Io: Reverse saturation Current (Amp)

q: Electron charge

V: Voltage across the diode

K: Boltzmann's constant

T: Junction temperature

$\mathrm{N}$ : Ideality factor of the diode

Rs: Series resistance

Rsh: Shunt resistance of the cell

\section{LIST OF COMPONENTS}

List of components used for the implementation are as listed in Table 1

Table-1: List of Component

\begin{tabular}{|l|l|l|l|}
\hline $\begin{array}{l}\text { Sl. } \\
\text { No }\end{array}$ & \multicolumn{1}{|c|}{ Component } & \multicolumn{1}{|c|}{ Specification } & Q'ty \\
\hline 1 & $\begin{array}{l}\text { ARM7-Development } \\
\text { Board }\end{array}$ & $\begin{array}{l}\text { MCB2140- } \\
\text { Evaluation Board }\end{array}$ & 1 \\
\hline 2 & Solar Panel & $\begin{array}{l}10 \mathrm{~W}, 21.5 \mathrm{~V}\left(\mathrm{~V}_{\mathrm{OC}}\right), \\
0.65 \mathrm{~A}\left(\mathrm{I}_{\mathrm{SC}}\right)\end{array}$ & 1 \\
\hline 3 & Battery & $12 \mathrm{~V}, 6 \mathrm{Ah}$ Lead & 1 \\
\hline
\end{tabular}




\begin{tabular}{|l|l|l|l|}
\hline & & Acid Battery & \\
\hline 4 & Stepper Motor & $\begin{array}{l}15 \mathrm{Kg} \\
\text { torque,4A/phase }\end{array}$ & 1 \\
\hline 5 & Motor Driver & L298 kit & 1 \\
\hline 6 & LDRs & & 4 \\
\hline 7 & LCD Display & $16 \mathrm{X} 2$ & 1 \\
\hline 8 & Relays & SPDT,DPDT & 2,1 \\
\hline 9 & Buck converter IC & LM2596 & 1 \\
\hline $\begin{array}{l}\text { Other miscellaneous components: Inductor-77 } \mu \mathrm{H}, \\
\mathrm{C} 1=47 \mu \mathrm{F}, \quad \mathrm{C} 2=330 \mu \mathrm{F}, \mathrm{C}_{\mathrm{FF}}=1 \mathrm{nF}, \mathrm{R}_{1}=4.6 \mathrm{~K} \Omega, \mathrm{R}_{2}=39 \mathrm{~K} \Omega, \\
\text { ULN2003,Schottky Diode-1N5822. }\end{array}$ \\
\hline
\end{tabular}

\subsection{ARM7-LCP2148 Kit}

The microcontroller used for development of this project is NXP's LPC2148 microcontroller [13,14,15].It is a 32bit microcontroller with advanced features. It has two ADCs(ADC16chanels and ADC0-8Chanels, a total 14 ADC pins). $40 \mathrm{~KB}$ of on-chip static RAM and $512 \mathrm{~KB}$ of on-chip flash program memory. In-Application/In-System Programming is possible via on-chip boot-loader software.CPU operating voltage ranges from 1.3 to $3.3 \mathrm{~V}(3.3 \mathrm{~V} \pm 10 \%)$ with $5 \mathrm{~V}$ tolerant $\mathrm{I} / \mathrm{O}$ pads. Up to $45,5 \mathrm{~V}$ tolerant fast general purpose $\mathrm{I} / \mathrm{O}$ pins in a tiny LQFP 64 package.

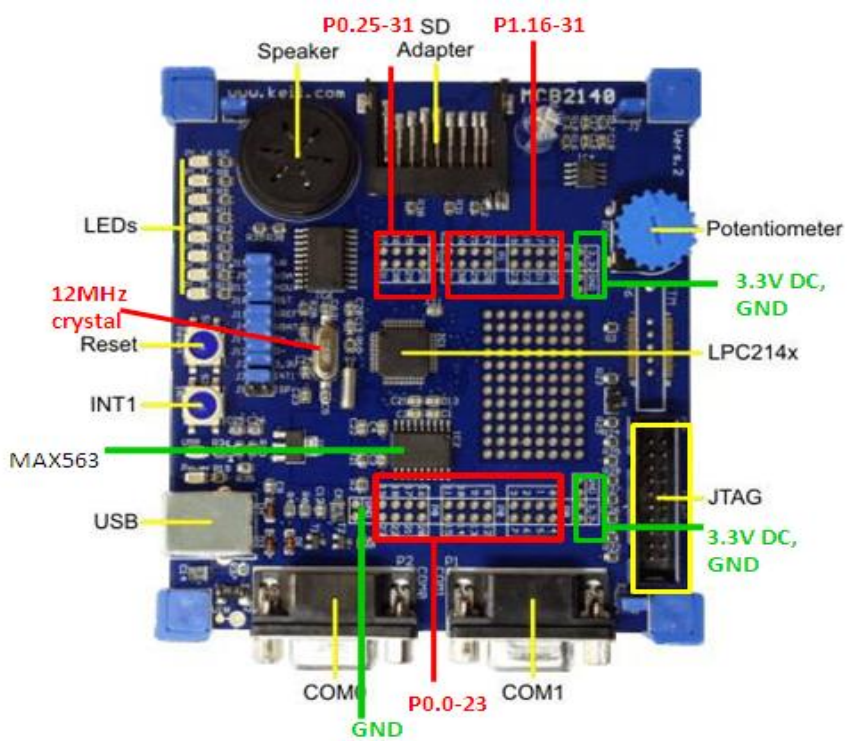

Fig- 3: NXPs MCB2140-Evaluation Board with feature as highlighted[13]

\subsection{Stepper Motor and Motor Driver}

Stepper motor runs on amount of current flowing through its windings $[9,10]$. By supplying appropriate current and voltage in a specified sequence we can control the rotation of the stepper either in clockwise or in anticlockwise direction. We can control the speed of the stepper by changing the frequency of the input sequence and also we can stop the stepper in a particular angle (at a particular step) to achieve a desired angle of rotation using control circuitry. The control circuit can be a microcontroller. But when we employ microcontroller as a control circuit, the output of the controller is about $3.3 \mathrm{~V}$ and current will be in terms of micro Amps this is a negligible current which is not sufficient for the coils to generate required torque. Hence Motor drivers are usually employed to achieve minimum current for stepper motor to work properly. The IC L298 is one such driver [12] used to drive a stepper motor. When we consider a stepper motor for an application, Torque plays a very important role. Here a $15 \mathrm{Kg}$ torque Stepper motor is used.
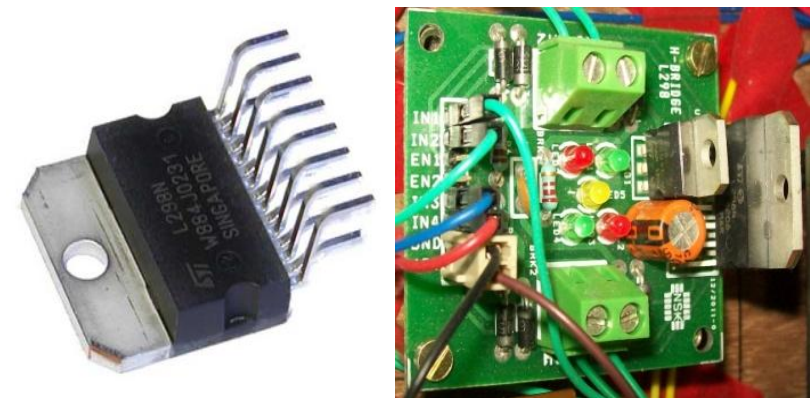

Fig- 4: L298 IC \& stepper motor diver kit [11]

The kit in figure 4 works on $12 \mathrm{~V}$ power supply. It has 4 inputs In1, In2, In, In4 (connected to controller). Four outputs C1, C2, C3, and C4 (to stepper motor). It can drive up to 4A load has Diodes to protect control circuit from back emf.

\subsection{LDRs}

Light Dependent Resisters are used for sensing the light intensity. LDRs [8] are connected as a part of voltage Divider circuit and output is given to the ADC pins of the $\mu$ controller.

\subsection{Relays}

Relays are used for switching the charging of battery either from solar panel or from AC source. These are also used to disconnect battery from charging; to prevent battery from overcharging (a DPDT relay is used) and reconnect battery when the battery voltage drops below the specified limit. Relays are controlled by the microcontroller.

\section{ANALYSIS OF BUCK CONVERTER}

Buck converter [3] is one type of DC-DC converter, which converts the DC input level to some lower DC voltage level hence this is a step down converter. It is a SMPS type converter employs MOSFET, Diode, Inductors and capacitors to achieve the voltage conversion $[3,4,5]$. A simple switch working as a buck converter is as shown in figure5 and related output waveforms in figure 6 


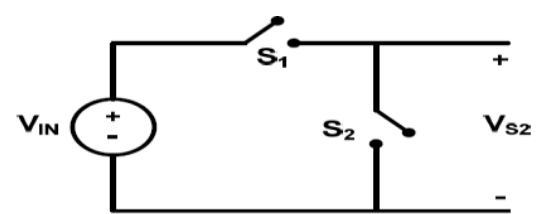

Fig-5:Buck convertor: Switches as building block[4].

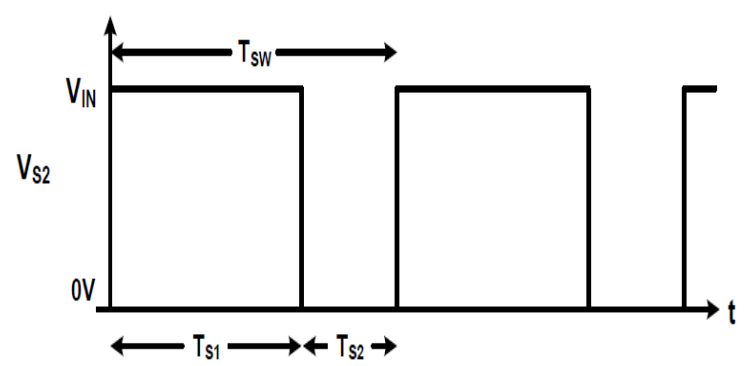

Fig-6: Output voltage wave form of buck convertor (of fig5.1)

Where switch S1 will be a MOFET and S2 be a Diode(Schottky diode).The Input and output voltages are related with $\mathrm{T}_{\text {on }}$ and $\mathrm{T}_{\text {off }}$ times of switches is given by the below equation (2)

$$
\mathrm{Vs} 2=\frac{1}{\mathrm{Tsw}, \mathrm{avg}} \int_{0}^{\mathrm{Tsw}} \mathrm{Vs} 2(\mathrm{t}) \mathrm{dt}=\frac{\mathrm{Ts} 1 . \mathrm{Vin}+\mathrm{Ts} 2.0}{\mathrm{Tsw}}=\mathrm{D} . \text { Vin } \ldots
$$

Equation (2) tells us that by controlling/varying the Duty cycle of the switches we can get a desired level of output. For example suppose if input is $24 \mathrm{~V}$ from a solar panel if the duty cycle is $50 \%$ then we will get $12 \mathrm{~V}$ as our output voltage.

The actual circuit diagram of buck converter is as shown in figure 7. The inductor and capacitor acts as low pass filter which removes the high frequency components from the input.

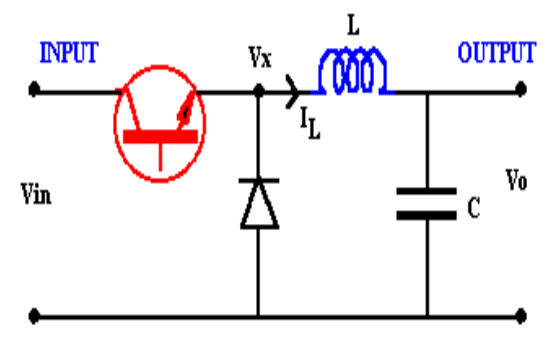

Fig-7: Buck converter

Buck converter with Transistor and Diode are main switching components Inductor along with capacitor acts as a filter to remove spurious frequency components.

Many Self regulated buck converters are available, which takes a variable DC as input and give a fixed DC voltage. One of such regulator is the LM2596. It is monolithic ICs that provide the entire active functions for a step-down (buck) switching regulator; this is capable of driving a $3 \mathrm{~A}$ load with excellent line- load regulation. And it is available in fixed output voltages of $3.3 \mathrm{~V}, 5 \mathrm{~V}, 12 \mathrm{~V}$, and also in adjustable output version. Figure 8 shows the circuit diagram of an adjustable output buck converter.

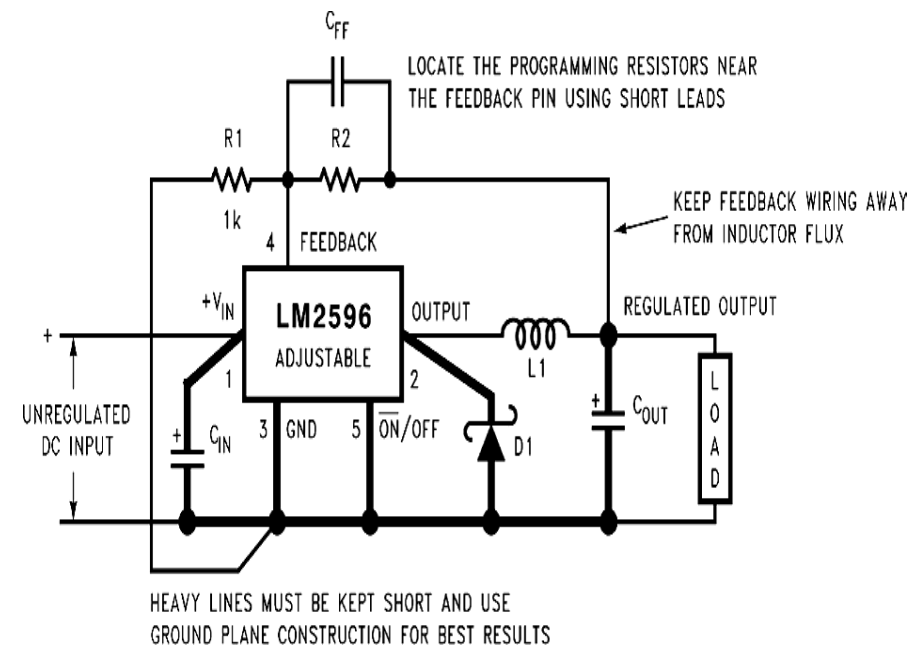

Fig-8: Circuit diagram of an Adjustable Output Voltage buck convertor [6].

\section{Designing the buck convertor for $12 \mathrm{~V}$ output:}

The design equation for $\mathrm{V}_{\text {out }}$ using LM2596 is

$$
\text { Vout }=\operatorname{Vref}\left(1+\frac{R 2}{R 1}\right)
$$

Where $\mathrm{V}_{\text {ref }}=1.23 \mathrm{~V}$

If $\mathrm{R}_{1}=4.6 \mathrm{~K} \Omega, 1 \%$ resistor, then value of $\mathrm{R}_{2}$ is found as

$$
\mathrm{R} 2=\mathrm{R} 1\left(\frac{\text { Vout }}{\text { Vref }}-1\right)=4.6 \mathrm{~K} \Omega\left(\frac{12 \mathrm{~V}}{1.23 \mathrm{~V}}-1\right)=39 \mathrm{~K} \Omega
$$

Notice that to charge a $12 \mathrm{~V}$ battery the source voltage has to be at least higher than the battery voltage and the charging current has to be at least $10 \%$ of specified capacity (i.e., Ampere Hours) of the battery, keeping this in mind, $\mathrm{R}_{2}$ can be

$$
\mathrm{R} 2=\mathrm{R} 1\left(\frac{\text { Vout }}{\text { Vref }}-1\right)=4.6 \mathrm{~K} \Omega\left(\frac{13 \mathrm{~V}}{1.23 \mathrm{~V}}-1\right)=44 \mathrm{~K} \Omega
$$

Selections of other components are made by referring the data sheets. $\mathrm{L}=77 \mu \mathrm{H}$ inductor. $\mathrm{C}_{\mathrm{in}}=47 \mu \mathrm{F}, \mathrm{C}_{\mathrm{ou}} \mathrm{t}=330 \mu \mathrm{F}$ both are electrolytic type. $\mathrm{CFF}=1 \mathrm{nF}$ ceramic capacitor used as a feedback which in parallel with R2 which removes the spurious high frequency components. A Schottky Rectifier diode is used (1N5822) as a second switch of buck converter.

The solar panel output is connected to the buck converter. Buck converter gives a fixed $12.5 \mathrm{~V}$ that can be used to charge a $12 \mathrm{~V}$ battery. 


\section{HARDWARE \& SOFTWARE INTEGRATION}

The circuit diagram of proposed system is as shown in figure 9

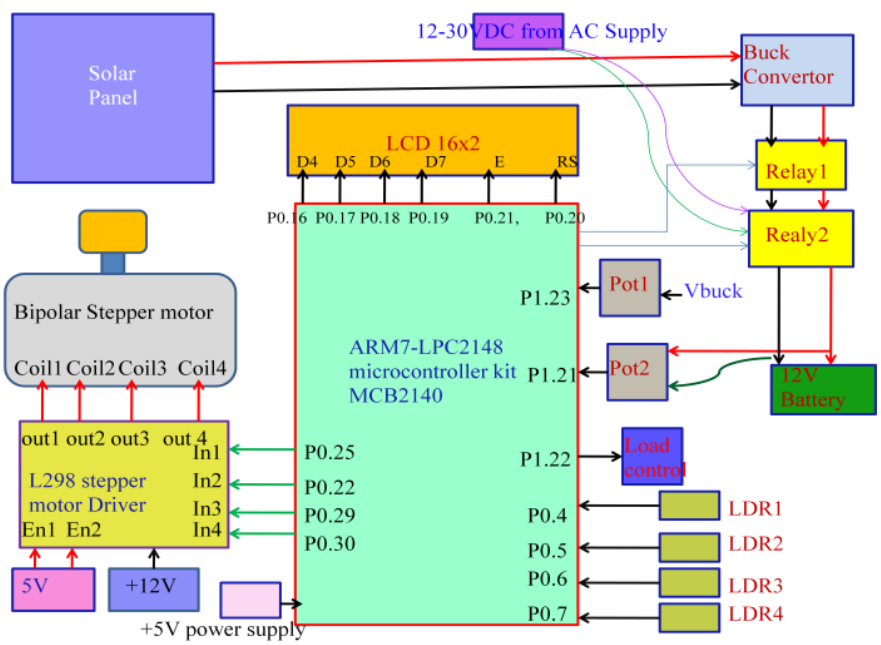

Fig-9: Block Diagram of proposed System

The Keil $\mu$ Vision4 software was usedfor the development and implementation of control program using embedded $\mathrm{C}$ for battery charger and solar tracker.

\subsection{Flowchart}

The flow chart of the control program for battery charger and solar tracker are as given in figure 10 and 11.

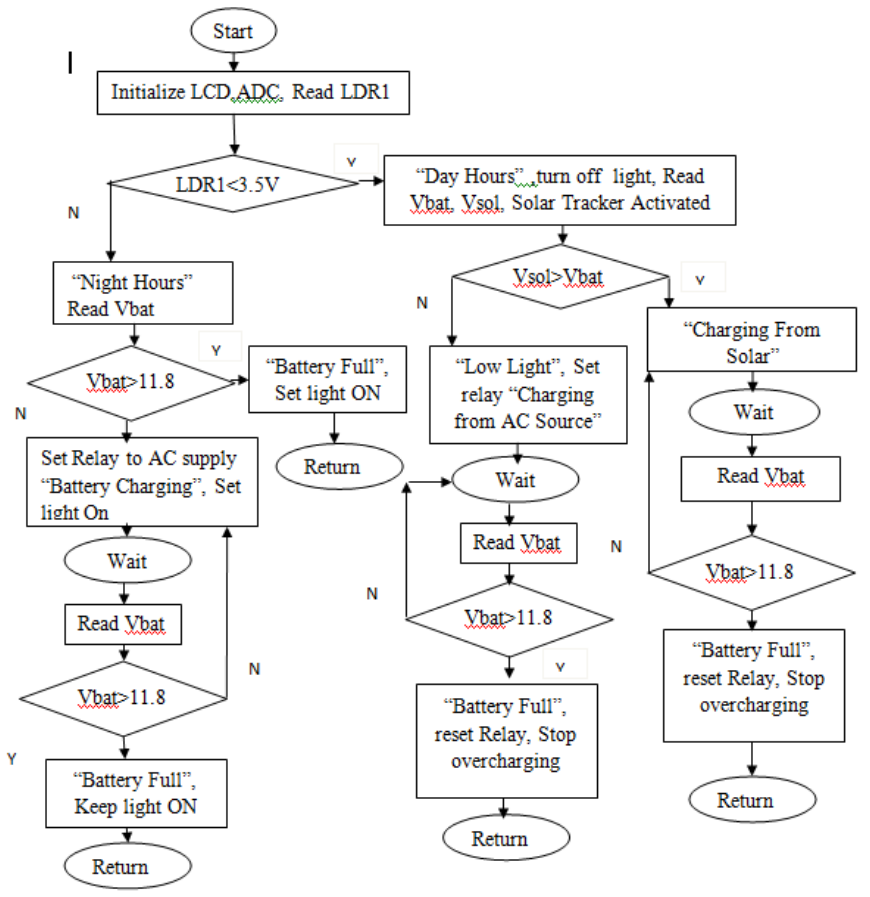

Fig-10: Flowchart of Solar Battery Charge Controller

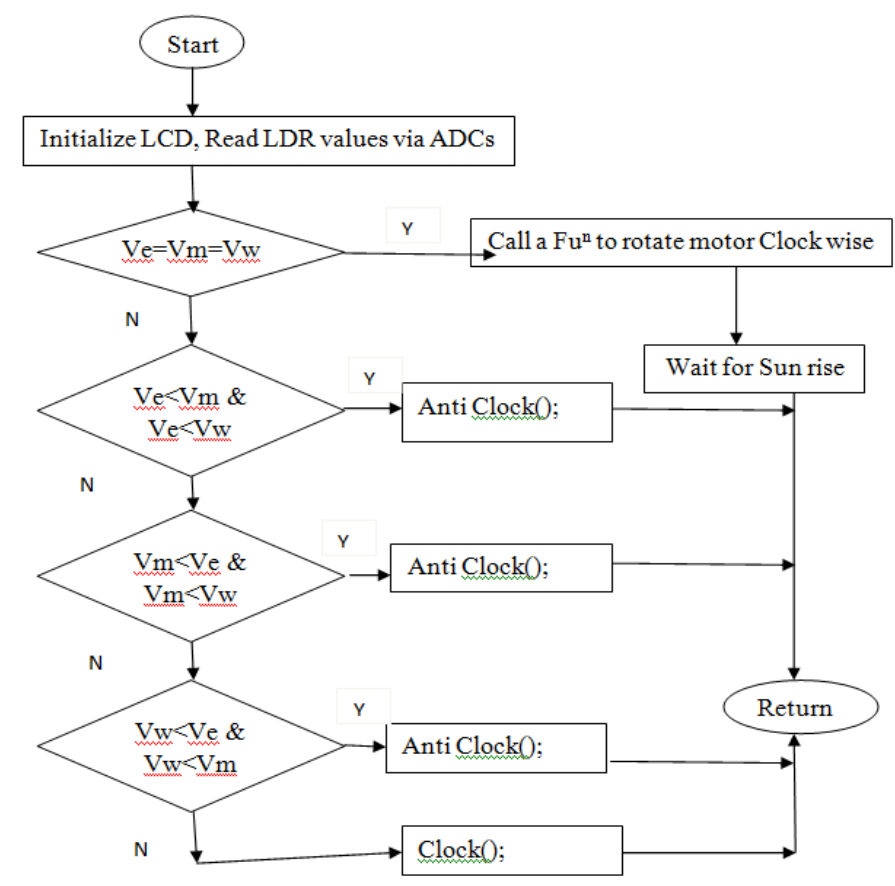

Fig-11: Flowchart of Solar Tracker

Where $\mathrm{Ve}, \mathrm{Vm}, \mathrm{Vw}$ are the corresponding output voltages of LDR kept to sense the sun position when it is in east, middle (noon) and west position respectively.

\section{RESULTS}

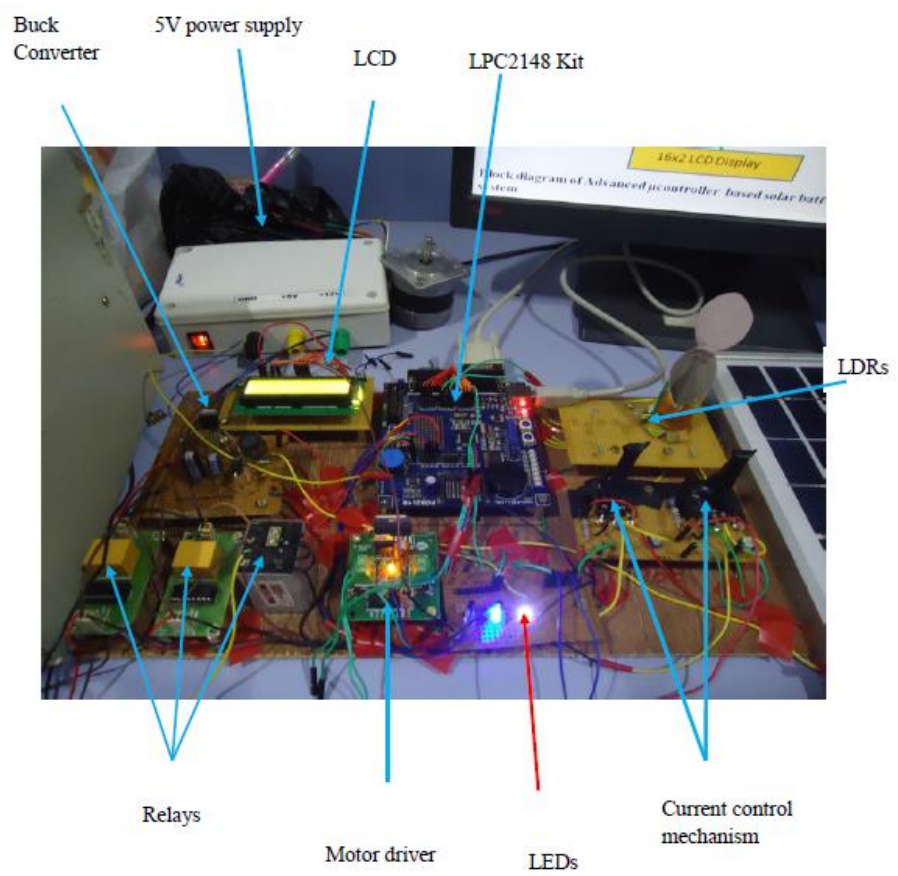

Fig-12: Final set up of battery charger 


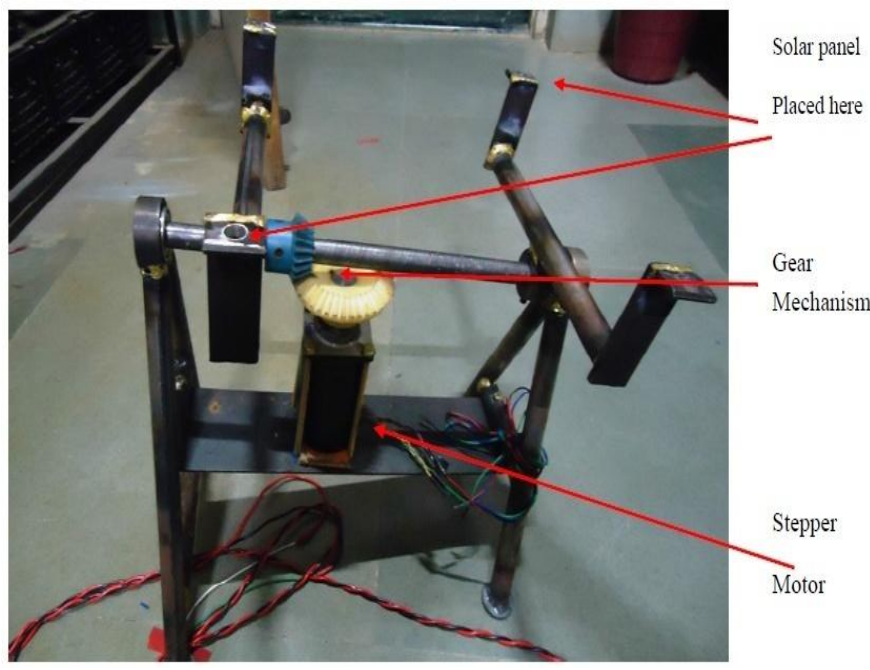

Fig-13: Solar tracker set up

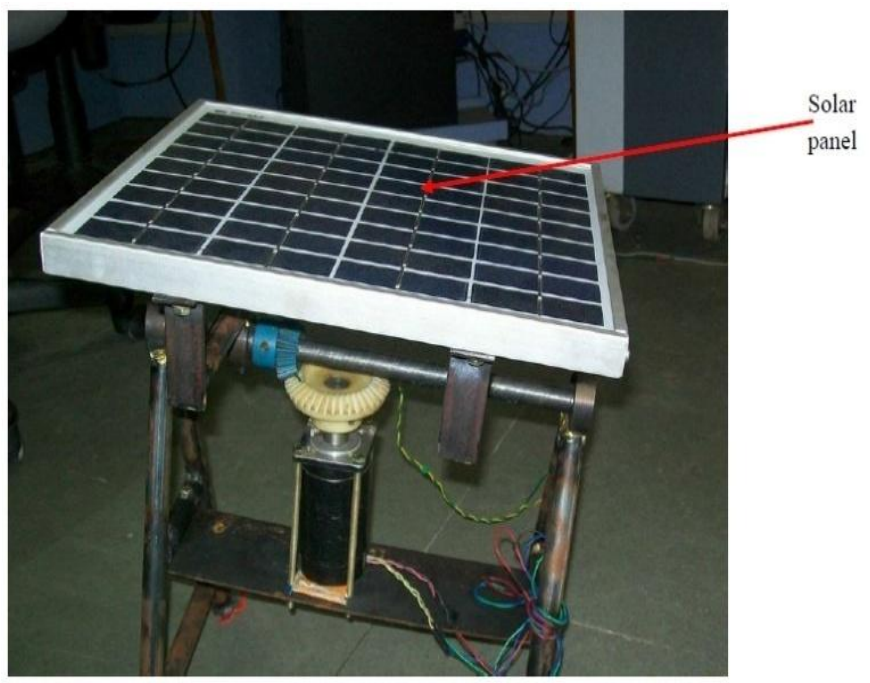

Fig-14: Solar tracker final set up

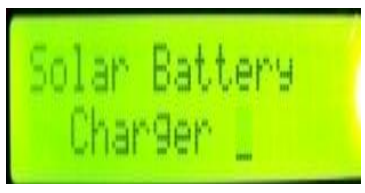

Fig-15a: System display when started first time or on reset

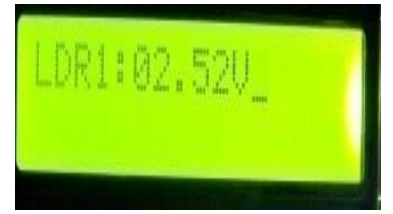

Fig-15b: Reading LDR1 value
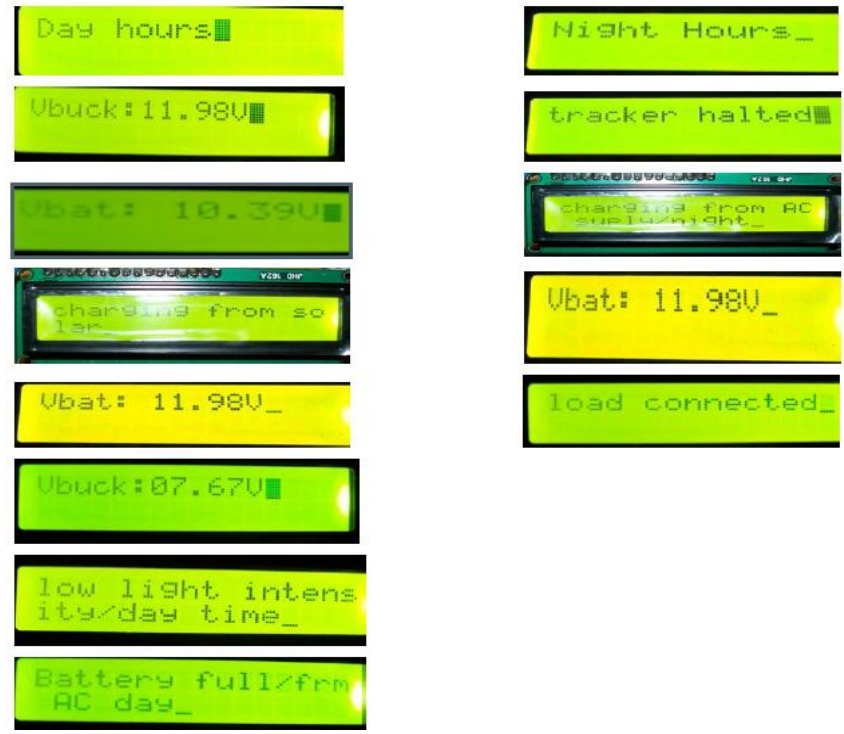

Fig-15c: Various Outputs displayed on LCD

\section{CONCLUSIONS}

For this project a $10 \mathrm{~W}$ PV panel is used to charge a $12 \mathrm{~V}, 6 \mathrm{Ah}$ battery. The work can be carried out further to charge a large battery backup using higher Wattage PV panels; for such cases the battery charger should be designed to handle large current and voltage range. The same battery charger designed here can be used with some modifications to handle the large current from both PV modules and Battery backup. Since the microcontroller which is the main part of the battery charger, takes a few $\mu$ Amps of current, hence even if you let a few milliamps of current into the $\mu$ controller's ADC pins, which may damage the pins permanently. Hence, care should be taken before giving anything to the ADC pins of the microcontroller.

The solar tracker designed here is a Single axial solar tracker, which tracks the sun moment in east-west direction. The design is suitable for a single PV panel and for roof mounted applications. The same can be carried out for multiple PV panels connected together and also for pole mounted PV panels; for those kinds of applications we require very high torque stepper motors (stepper motor driver has to be designed to handle large current required to drive these motors).And we need to design gear mechanisms to handle the weight which the stepper motor couldn't handle directly.

\section{REFERENCES}

[1] http://www.cea.nic.in/reports/articles/god/renewable_ener gy.pdf

[2] The physics of solar cellswww.worldscientific.com/worldscibooks/10.1142/p276.

[3] Buck_boost_basics.pdf

[4] Jaycar Electronics Reference Data Sheet: DCDCCONV.PDF 
[5] LM2596 SIMPLE SWITCHER-Power Converter 150

kHz 3A Step-Down Voltage Regulator

[6] Batteries- www.autoshop101.com/forms/h6.pdf

[7] Solar Trackers - www.prlog.org/11668462-solar-trackerssingle-vs-dual-axis.htm

[8] Photo resistor-www.wikipedia.com

[9] Stepper motors- www.wikipedia.com

[10] Stepper Motor Hi-torque 15 Kg.cm-57BYGH311-01

[11] Motor diver kit- www.solarbotics.com/products/k_cmd

[12] L289-stepper motor Driver.

[13] UM10139 Volume 1: LPC214x User Manual

[14] LPC2141/42/44/46/48 datasheet.

[15] Introduction to LPC200- lpc-arm-book rev10-screen.pdf

[16] Solar cells and their applications $2^{\text {nd }}$ Edition-LEWIS FRAAS and LARRY PARTAIN

[17] Fundamentals of Photovoltaic Modules and Their Applications- G. N. Tiwari and SwapnilDubey-Centre for Energy Studies, Indian Institute of Technology (IIT) Delhi, India

\section{BIOGRAPHIES:}

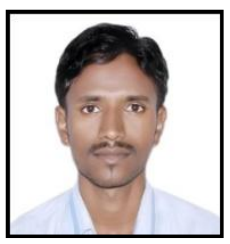

Maruti Pammar, I am from Gajendragad (Rona Tq, GadagDist, Karnataka), I have completed M.Tech in Digital Electronics and Communication from MS Ramaiah Institute of Technology Bangalore in Sept 2013 with Distinction. Presently I am working as a Physics Tutor in a private Institute (ASAP Tutor Pvt Ltd Bangalore).

Area of Interest: Power Electronics, Smart Grid Systems, Supper Conductors, Renewable Energy Resources, MicroElectro Mechanical Systems(MEMS), Embedded SystemsMicrocontrollers (ARM7, MSP430, 8051), Logic design, HDL/Verilog programming.

Contact Details: +919611251241

e-mail: marutip36@gmail.com

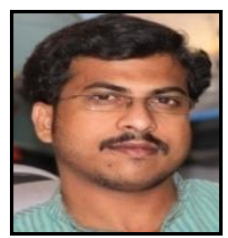

Santosh Chavan, I am from Bijapur (Ramatirth, Atharga post, Indi Tq, BijapurDist, Karnataka). I have done M.Tech in Digital Electronics and Communication from MS Ramaiah Institute of Technology Bangalore in Sept 2013 with Distinction. I am currently working as an Asst. Professor in RajaRajeswari Collage of Engineering Bangalore.

Area of Interest: Embedded Systems-Microcontrollers (ARM7, 8051), Logic design, HDL/Verilog programming, computer communication and networking, Circuit analysis, Optical fiber communication, wireless communication, Linear integrated circuits.

Contact Details: +919739736421 e-mail: san.mpsc@ gmail.com 